Pediat. Res. 4: 257-261 (1970)

Adrenal dysplasia anencephaly kidney

\title{
Renal Development in Dysplasia of the Fetal Pituitary
}

\author{
Richard L. NAeye ${ }^{[18]}$, William Blanc and ANn M. Milic \\ Department of Pathology, the Pennsylvania State University College of Medicine, Hershey, Pennsylvania, \\ and Departments of Pathology and Obstetrics and Gynecology, College of Physicians and Surgeons, \\ Columbia University, New York, New York, USA
}

\begin{abstract}
Extract
Thirty-one newborns with anencephaly had small kidneys; the weights of these organs were only $67 \%$ of the mean value for control infants of the same gestational age. Kidneys of the anencephalic infants had only $81 \%$ as many nephrons as kidneys of the control infants. In the kidneys of anencephalic newborns, tubular cells distal to the proximal convoluted tubules contained less cytoplasm than did comparable cells of control subjects. For example, in anencephalic infants, cells in the distal convoluted tubules had only $57 \%$ as much cytoplasm as control cells. Pituitary dysfunction may be directly or indirectly responsible for this maldevelopment, since in this study, an infant with isolated congenital absence of the pituitary had similar renal abnormalities while a newborn anencephalic infant with a normal parabiotic twin partner had near normal kidneys.
\end{abstract}

\section{Speculation}

Dysfunction of the hypothalmic-neurohypophyseal system might contribute to the hydramnios common in anencephalic gestations by leading to increased urine output by the fetus. In any case, nephron structure is so abnormal in anencephalic newborns that it should be interesting to test their renal function.

Introduction

The pituitary gland is usually present in anencephalic neonates but it is almost always abnormal. Anterior lobe acidophils are reported to be subnormal in number and there are fine structural evidences of subnormal secretory activity $[2,5,6]$. End organ manifestations of this anterior lobe dysfunction are found in the adrenals and the epididymus [2, 16]. Although several investigators have reported that the posterior lobe of the pituitary is structurally and functionally abnormal in such infants, no studies of their renal structure or function have been published $[2,3,11]$. The present study was undertaken to search for possible renal abnormalities associated with presumed prenatal hypothalamicneurohypophyseal dysfunction in anencephaly. Quantitative morphologic methods were used and results suggest that specific renal abnormalities may be directIy or indirectly related to prenatal pituitary dysfunction.

\section{Case Material}

Autopsy material was examined from 69 anencephalic infants who were stillborn or died in the immediate 
neonatal period at Sloane Hospital for Women, New York City, or at the hospitals affiliated with the University of Vermont. Infants used had gestational ages ranging from 28 to 50 weeks as calculated from the mother's statement of her last menstrual period. Detailed quantitative histologic studies were undertaken on the tissues of the 31 cases who had no gross renal malformations. Their gestational ages ranged from 38 to 46 weeks.

The anencephalic infants were compared with 20 full-term control infants who had birth weights within $10 \%$ of mean normal term values [11]. Six of these control infants were actually postterm, their gestational ages varying from 42 to 46 weeks. No cases with congenital anomalies, erythroblastosis fetalis, features of congenital infections, diabetic or toxemic mothers were included in the control group. In the control cases, death was usually related to pulmonary hemorrhage, cerebral hemorrhage, fetal or intrapartum hypoxia.

Two additional cases were added to the study to further define the role of the pituitary in renal development in the fetus. A full-term neonatal male infant who had a normal brain but absent pituitary was examined. Also studied was an anencephalic twin of 34-weeks gestation who died in the neonatal period. This anencephalic female had a completely normal partner who survived. Injection of the monochorionic placenta demonstrated several large artery-to-artery anastomoses which presumably permitted a parabiotic exchange of blood between the two twin partners before birth [7].

\section{Methods}

Organ weights and body measurements were obtained from autopsy protocols. In each case, weights and measurements of body size and organs were calculated as percentages of mean values for control infants of the same gestational age [12].

Mean values for our control group were within a few percentage points of published figures [12].

The percentage of cortex, inner, and outer zones of the medulla was determined for each kidney by using a planimeter on camera lucida drawings of cross sections of the organ.

The method of line sampling was used to quantitate individual components in the various organs $[8,15]$. In this method, random microscopic fields are projected onto measured lines with a camera lucida. Each tissue component to be analyzed (i.e., cell, cell component or larger structure) is measured along the line at those points where it intersects the line. By this means, the approximate percentage of various com- ponents comprising a tissue can be determined. In addition, relative sizes and numbers of cells and cellular components can be calculated. In most instances, multiple sections of each organ were examined using this technique. In virtually every instance more than 100 cells of an individual cell type were measured.

After determining the number of individual components in individual cases, a mean value for each component was calculated for the anencephalic infants as a group. A comparison between groups was made of the relative number of each component. Details of calculations using these methods have previously been published [8].

The processing of tissues for histologic quantitation leads to shrinkage artifacts so that values recorded in the current study cannot be directly transposed to living tissues. All tissues were fixed in buffered, neutral formalin for $48 \mathrm{~h}$. Since similar fixation was used for study and control tissues, artifacts presumably were relatively constant throughout, permitting valid comparisons between groups and individual cases. The $t$ test was used to determine the significance of abnormal organ weights, cellular dimensions, and cell numbers.

\section{Results}

Body and most organ weights were subnormal in the anencephalic infants (table I). Body weight was not corrected for the absent brain. If such a correction were made, the mean body weight of the 31 anencephalic infants would be approximately $85 \%$ of control values [12]. The most striking abnormality was in the adrenal glands which weighed on the mean only $8.0 \%$

Table I. Mean body and organ values in newborns in percentage of control values ${ }^{1}$

\begin{tabular}{|c|c|c|c|}
\hline \multirow[t]{2}{*}{ Organs, wt } & \multicolumn{3}{|c|}{ Anencephaly } \\
\hline & $\begin{array}{c}\text { Anen- } \\
\text { cephaly } 2\end{array}$ & $\begin{array}{l}\text { with } \\
\text { normal } \\
\text { twin }^{3}\end{array}$ & $\begin{array}{c}\text { Absent } \\
\text { pituitary }\end{array}$ \\
\hline Body & $72.1^{4}$ & 115.8 & 113.8 \\
\hline Heart & $66.7^{4}$ & - & 109.2 \\
\hline Liver & $78.1^{4}$ & - & 107.8 \\
\hline Spleen & $86.1^{4}$ & 52.1 & 167.1 \\
\hline Kidney & $66.8^{4}$ & 124.4 & 65.6 \\
\hline Adrenal & $8.0^{4}$ & 69.3 & 7.8 \\
\hline
\end{tabular}

1 From reference [12].

${ }^{2}$ Average values.

${ }^{3}$ Value for individual case.

${ }^{4} P \leqq 0.05$ in comparison with control values. 
of control values (table I). This adrenal abnormality was also present in the newborn with the absent pituitary but the parabiotic anencephalic twin had adrenals of near normal size (table I). This latter neonate is the only anencephalic infant we found who had nearly normal adrenal glands; in no other case of anencephaly did the two adrenal glands together weigh more than $1.5 \mathrm{~g}$ and in all but two cases, the combined weight was less than $1.0 \mathrm{~g}$.
Quantitative histologic measurements revealed abnormalities in the single born anencephalic infants and in the newborn with the absent pituitary. Although cells in the various parts of the nephrons had normalsized nuclei, cytoplasmic mass was invariably subnormal, often markedly so (table II). Cytoplasmic values in the parabiotic twin were near normal values (table II). A moderate reduction was observed in the number of nephrons in most of the cases (table III).

Table II. Measurement of renal components in newborns in percentage of mean control values derived from 20 term and postterm infants

\begin{tabular}{|c|c|c|c|}
\hline Renal components & Anencephaly ${ }^{1}$ & $\begin{array}{l}\text { Anencephaly } \\
\text { with normal twin }{ }^{2}\end{array}$ & Absent pituitary ${ }^{2}$ \\
\hline \multicolumn{4}{|l|}{ Glomeruli } \\
\hline Mean diameter & 94 & 92 & 94 \\
\hline \multicolumn{4}{|l|}{ Proximal convoluted tubules } \\
\hline Diameter of nuclei & 96 & 108 & 97 \\
\hline Gytoplasm per cell & $76^{3}$ & 89 & 72 \\
\hline \multicolumn{4}{|l|}{ Thin segment of Henle's loop } \\
\hline Diameter of nuclei & 98 & 101 & 95 \\
\hline Cytoplasm per cell & $57^{3}$ & 121 & 48 \\
\hline \multicolumn{4}{|l|}{ Distal convoluted tubules } \\
\hline Diameter of nuclei & 96 & 94 & 108 \\
\hline Cytoplasm per cell & $57^{3}$ & 89 & 38 \\
\hline \multicolumn{4}{|c|}{ Collecting tubules in outer zone of medulla } \\
\hline Diameter of nuclei & 101 & 91 & 112 \\
\hline Cytoplasm per cell & $59^{3}$ & 75 & 37 \\
\hline \multicolumn{4}{|c|}{ Collecting tubules in inner zone of medulla } \\
\hline Diameter of nuclei & 100 & 110 & 111 \\
\hline Cytoplasm per cell & $52^{3}$ & 88 & 43 \\
\hline Luminal area of tubules & $30^{3}$ & & \\
\hline
\end{tabular}

1 Average values.

2 Value for individual case.

${ }^{3} P \leqq 0.05$ in comparison with control values.

Table III. Number of organ structures in newborns in percentage of control values derived from 20 term and postterm infants

\begin{tabular}{lccc}
\hline Kidneys & Anencephaly ${ }^{1}$ & $\begin{array}{c}\text { Anencephaly } \\
\text { with normal twin }{ }^{2}\end{array}$ & Absent pituitary ${ }^{2}$ \\
\hline Glomeruli & $81^{3}$ & 92 & 82 \\
Proximal convoluted tubules & $81^{3}$ & 88 & 88 \\
Distal convoluted tubules & $77^{3}$ & 93 & 78 \\
Tubules in Henle's loop & $80^{3}$ & 89 & 79 \\
Collecting tubules & $80^{3}$ & 95 & 90 \\
\hline
\end{tabular}

1 Average values.

${ }^{2}$ Value for individual case.

${ }^{3} P \leqq 0.05$ in comparison with control values. 


\section{Discussion}

Results of the study indicate that newborns with anencephaly have a moderate-to-marked cytoplasmic deficiency in cells of the nephron distal to the proximal convoluted tubules.

This abnormality was not found in any other body organ (unpublished report). Several lines of evidence suggest pituitary dysfunction as a likely cause for this hypoplasia of renal cells. First, an infant with isolated congenital absence of the pituitary had similar nephron abnormalities, whereas an anencephalic infant with a normal parabiotic twin had near normal nephron structure. Humoral substances from the pituitary of the normal monovular twin presumably reached the anencephalic partner because this latter infant had almost normal adrenal glands. Transplacental arteryto-artery anastomoses, which were demonstrated after birth, presumably permitted exchange of blood-borne humoral substances between the twin partners during fetal life [7].

There is other evidence that a normally functioning hypothalamic-neurohypophyseal system is lacking in anencephalic newborns. Only about one-quarter of the pituitary glands of anencephalic infants have a pars nervosa and only one-third a pars intermedia [2]. Two reports indicate that posterior lobe cells with secretory material are either sparsely present or absent in such infants $[3,11]$. Dysfunction of the hypothalamic-neurohypophyseal system might contribute to the hydramnios common in anencephalic gestations by leading to an increased fetal urine output $[3,10,14]$. In 2 anencephalic infants studied by BENIRSCHKE and MaKay [3], the posterior lobe of the pituitary was devoid of antidiuretic substance; one of the infants who was associated with oligohydramnios had secretory ganglion cells in its rudimentary brain while the other infant who was accompanied by marked polyhydramnios had no such secretory cells. The exact relation of antidiuretic hormone $(\mathrm{ADH})$ release to prenatal renal function remains to be determined because there is evidence that the kidney of the newborn is not fully responsive to the hormone [1, 4, 13]. If $\mathrm{ADH}$ does play an important role in antenatal renal function it probably has a fetal origin because it is unlikely that the hormone can cross the placenta in appreciable quantities [3].

Since no area of the nephron was completely normal in anencephalic infants it is far from certain that an $\mathrm{ADH}$ deficiency was solely responsible for the dysplasia. It is quite possible that a deficiency of other humoral substances derived from the pituitary or from the adrenal, contributed to the cellular hypoplasia. As already mentioned, all lobes of the pituitary, as well as the adrenals, are abnormal in anencephalic neo- nates. It would be less likely that the renal abnormality might be a primary defect related to the factor or factors that induced the anencephaly.

Finally, it must be asked if postmaturity could have contributed to the renal abnormalities since many of the anencephalic neonates had gestations longer than 42 weeks. A previous study [9] showed that postterm neonates who are undernourished have a subnormal number of glomeruli while normally nourished postterm infants have near normal kidney structure. The most characteristic feature of prenatal undernutrition is a reduced mass of cytoplasm in cells of most organs [9]. Since all organs but the kidneys in our anencephalic infants had cells with a normal amount of cytoplasm, it is unlikely that these malformed infants were undernourished before birth.

\section{Summary}

Thirty-one anencephalic infants had somewhat subnormal numbers of glomeruli and a substantial reduction of cytoplasm in cells of the nephron distal to the proximal convoluted tubules. An infant with isolated congenital absence of the pituitary gland had similar renal abnormalities, while a newborn anencephalic infant with a normal parabiotic twin partner had near normal kidneys.

\section{References and Notes}

1. Ames, R.G.: Urinary water excretion and neurohypophyseal function in full term and premature infants shortly after birth. Pediatrics 11: 272 (1953).

2. Angevine, D. M. : Pathologic anatomy of the hypophysis and adrenals in anencephaly. Arch. Path. 26: 507 (1938).

3. Benirschke, K. and MaKAy, D.G.: The antidiuretic hormone in fetus and infant. Obstet. Gynec., N.Y. 1: 638 (1953).

4. HeLler, H.: The water metabolism of newborn infants and animals. Arch. Dis. Childh. 26: 195 (1951).

5. Johannisson, E.: The foetal adrenal cortex in the human. Its ultrastructure at different stages of development and in different functional states. Acta endocrin., Kbh. 58: suppl. 130 (1968).

6. MOERr, E.: Adrenals of fetus, newborn, nursling and child: relation to pituitary; pathology of anencephalus. Acta endocrin., Kbh. 8: 259 (1951).

7. NAEYE, R. L.: Human intrauterine parabiotic syndrome and its complications. New Engl.J.Med. 268: 804 (1963).

8. NAEYE, R.L.: Organ and cellular development in 
mice growing at simulated high altitude. Lab. Invest. 15: 700 (1966).

9. NAEYe, R.L.: Infants of prolonged gestation, a necropsy study. Arch. Path. 84: 37 (1967).

10. Nichols, J.: Polyhydramnios in anencephaly. J. amer. med. Ass. 197: 549 (1966).

11. Pinner-Poole, B.: Absence of neurosecretory material in the pituitary glands in anencephaly. $\mathrm{J}$. Neuropath. exp. Neurol. 26: 117 (1967).

12. Schulz, D.M.; Giordano, D.A. and Schulz, D.H.: Weights of organs of fetuses and infants. Arch. Path. 74: 244 (1962).

13. Smith, F.G. Jr.; Sarivens, B. and Borden, N.: Effects of extrauterine maturation on blood and urine chemical values of the premature infant. $\mathrm{J}$. Pediat. 66: 997 (1965).

14. Stevenson, A. C.: Association of hydramnios with congenital malformations. Ciba Found. Symp. Congenital Malformations, p.241 (Little, Brown, Boston 1960).
15. Uotila, U. and Kannas, O.: Quantitative histological method of determining proportions of principal components of thyroid tissue. Acta endocrin., Kbh. 11: 49 (1952).

16. Zondek, L.H. and ZondeK, T.: The secretory activity of the human epididymus in anencephaly. Ann. Pediat. 204: 301 (1965).

17. Supported by Public Health Service Research Grant no. HE 11688-02, National Institute of Child Health and Human Development Grant no. 2-T01-HD0018-04 and Career Scientist Program of the Health Research Council of the City of New York, Contract no. 1-300.

18. Requests for reprints should be directed to: RicrARD L. Naeye, M.D., Department of Pathology, M.S. Hershey Medical Center, Hershey, Pennsylvania 17033 .

19. Accepted for publication October 3, 1969. 